\title{
Temperamen Bayi dan Kondisi Psikososial Ibu Postpartum
}

\author{
Dini Kurniawati* \\ *Program Studi Ilmu Keperawatan Universitas Jember \\ Jl. Kalimantan No 37 Jember, Jawa Timur \\ Email: dini_psikunej10@yahoo.com
}

\begin{abstract}
Abstrak
Kondisi psikososial ibu merupakan keadaan emosi, psikologis yang akan mempengaruhi peran pengasuhan, perilaku bayi atau temperamen bayi, kesehatan dan kesejahteraan seseorang. Penelitian ini bertujuan untuk mengidentifikasi hubungan antara temperamen bayi dengan kondisi psikososial ibu pada masa postpartum. Metode penelitian ini adalah korelasi dengan pendekatan cross-sectional. Sampel penelitian ini adalah ibu postpartum hari ke 2-3 yang dirawat di rumah sakit sebanyak 121 ibu dengan consecutive sampling. Instrumen yang digunakan adalah postnatal risk questionnaire (PNRQ) untuk mengukur kondisi psikososial ibu postpartum dan untuk mengukur temperamen bayi menggunakan ICQ pada dimensi difficult yang telah dimodifikasi. Analisis data menggunakan analisis univariat dengan menggunakan proporsi dan analisis bivariat dengan Chi-Square. Hasil penelitian menunjukan bahwa lebih dari setengah responden mempunyai pendidikan menengah $(52,9)$, primipara (51,9\%), dan status ekonomi rendah (58,7\%). Sedangkan hasil analisis bivariat menunjukan adanya hubungan antara temperamen bayi dengan kondisi psikososial ibu postpartum ( $p=0,001$; $\mathrm{OR}=12,56 ; 95 \%$ CI 4.35-36.4). Ibu dengan bayi yang mempunyai temperamen mudah akan membantu ibu untuk memiliki kondisi psikososial yang tidak berisiko. Untuk mencegah gangguan psikososial ibu perlu adanya pengkajian risiko psikososial pada ibu postpartum dan menfasilitasi ibu mengenal temperamen bayinya.
\end{abstract}

Kata Kunci : kondisi psikososial ibu postpartum, temperamen bayi

\section{Pendahuluan}

Psikososial merupakan kondisi emosi, psikologis dalam keadaan cemas, depresi, distres yang berhubungan dengan budaya, sosial, spiritual yang dapat memengaruhi kesehatan dan kesejahteraan seseorang (Priest, Austin, Barnett, \& Buist, 2008). Beberapa kondisi psikososial pada ibu postpartum antara lain kecemasan, depresi, post trauma serta psikopatologi dan sifat egosentris ibu (Moynihan, 2014; \& Muzik et al, 2013).

Depresi perinatal pada ibu postpartum menunjukan angka yang meningkat. Hasil survey menunjukan depresi perinatal dikalangan perempuan Asia cukup tinggi dengan prevalensi ansietas dan depresi adalah $20 \%$ dari keseluruhan perempuan hamil (Agampodi et al., 2012). Depresi pada masa kehamilan hampir $7-15 \%$ di negara berkembang, 19-25\% di negara yang lain, berbanding $10 \%$ pada masa persalinan dan $7 \%$ pada masa di luar perinatal. Kejadian depresi antara ibu hamil dengan ibu postpartum adalah $7,4 \%-20 \%$ pada masa antenatal dan sampai $19,2 \%$ pada tiga bulan pertama setelah melahirkan.

kondisi psikososial ibu postpartum perlu mendapatkan perhatian karena akan berdampak pada hubungan antara ibu dan bayi pada perkembangan selanjutnya. Kondisi psikososial yang dapat mengganggu hubungan antara ibu dan bayi antara lain riwayat trauma masa lalu. Ibu yang mengalami kekerasan dalam rumah tangga, 
kekerasan seksual, dan penelantaraan saat masa kanak kanak akan mengalami kesulitan dalam menjalin ikatan dengan bayinya (Colman \& Wildom, 2004; \& Rodger et al, 2004). Ibu dengan trauma pada masa anak-anak seperti penelantaran dan pelecehan seksual akan menilai dirinya negatif dalam berperan menjadi orang tua dan sering melakukan hukuman fisik, bermusuhan, dan tidak tertarik dalam mengasuh anaknya sehingga mengurangi keeratan ikatan dengan bayinya (Alexander et al, 2000; \& Banyard, Williams, \&Siegel, 2003).

Kondisi psikososial pada ibu postpartum dipengaruhi oleh beberapa hal antara lain temperamen bayi. Temperamen bayi merupakan status emosional, mood, dan perilaku yang unik dari bayi (Plaza, 2010). Temperamen bayi merupakan salah satu perilaku instingtif bayi seperti reaksi menangis, senyum, dan gerakan. Temperamen bayi memengaruhi ibu dalam mengasuh bayinya sehingga mempengaruhi kondisi psikososial ibu. Hasil penelitian menunjukan bahwa temperamen bayi dapat dipengaruhi dan memengaruhi lingkungan serta hubungan dengan ibu untuk beradaptasi dan mengasuh bayinya (Mayseless \& Scher, 2000).

Berdasarkan hal ini, perlu dilakukan penelitian untuk menjawab pertanyaan penelitian yang utama yaitu "Bagaimanakah hubungan antara temperamen bayi dengan kondisi psikososial ibu postpartum ?"

\section{Metode}

Penelitian ini merupakan penelitian korelasi dengan pendekatan cross-sectional. Sampel penelitian ini adalah ibu postpartum yang sedang dirawat di RSUD X Situbondo, sebanyak $121 \mathrm{ibu}$. Consecutive sampling digunakan untuk menentukan sampel tersebut.
Instrumen untuk mengukur kondisi psikososial ibu postpartum adalah postnatal risk questionnaire (PNRQ) yang terdiri dari 12 item pertanyaan Sedangkan intrumen untuk mengukur temperamen bayi menggunakan ICQ pada dimensi difficult yang telah dimodifikasi.

Analisis pada penelitian ini adalah analisis univariat dan analisis bivariat. Analisis bivariat untuk mengetahui hubungan masing masing faktor dengan psikososial ibu postpartum menggunakan analisis ChiSquare.

\section{Hasil}

Seluruh responden sebanyak 121 berpartisipasi dalam penelitian ini. Hasil analisis univariat responden seperti pada tabel 1.

Tabel 1 . Karakteristik Responden

\begin{tabular}{lrr}
\hline \multicolumn{1}{c}{ Karakteristik Ibu } & $\begin{array}{c}\text { Frekuensi } \\
(\mathrm{n})\end{array}$ & $\begin{array}{r}\text { Persentase } \\
(\%)\end{array}$ \\
\hline Usia Ibu & 42 & 34.7 \\
Usia Remaja & 79 & 65.3 \\
Usia Dewasa & & \\
Pendidikan & 48 & 39.7 \\
Pendidikan Dasar & 64 & 52.9 \\
Pendidikan Menengah & 9 & 7.4 \\
Pendidikan Tinggi & & \\
Paritas & 62 & 51.2 \\
Primipara & 59 & 48.8 \\
Multipara & & \\
Status Ekonomi & 71 & 58.7 \\
Sosial ekonomi rendah & 50 & 41.3 \\
Sosial ekonomi tinggi & & \\
Temperamen Bayi & 23 & 19 \\
Sulit & 98 & 81 \\
Tidak Sulit & & \\
Kondisi Psikososial & 35 & 28.9 \\
Berisiko & 86 & 71.1 \\
Tidak berisiko & & \\
&
\end{tabular}

Hasil analisis univariat menunjukan bahwa lebih dari setengah responden mempunyai pendidikan menengah $(52,9 \%)$, primipara 
$(51,9 \%)$, dan status ekonomi rendah $(58,7 \%)$.

bayi dengan kondisi psikososial ibu pada masa postpartum dapat dilihat pada tabel 2.

Sedangkan Analisis bivariat untuk mengetahui hubungan antara temperamen

Tabel 2. Hasil analisis bivariat

\begin{tabular}{|c|c|c|c|c|c|c|}
\hline \multirow[t]{3}{*}{ Variabel Independen } & \multicolumn{6}{|c|}{ Variabel Psikososial Pada Masa Postpartum } \\
\hline & \multicolumn{2}{|c|}{ Berisiko } & \multicolumn{2}{|c|}{ Tidak berisiko } & \multirow{2}{*}{$\begin{array}{c}\text { OR } \\
(95 \% \text { CI })\end{array}$} & \multirow[t]{2}{*}{ P-value } \\
\hline & $\mathbf{n}$ & $\%$ & $\mathbf{n}$ & $\%$ & & \\
\hline Temperamen Bayi & & & & & 12.56 & 0.001 \\
\hline Sulit & 17 & 73.9 & 6 & 26.1 & $(4.35 ; 36.4)$ & \\
\hline Tidak Sulit & 18 & 18.4 & 80 & 81.6. & & \\
\hline
\end{tabular}

Analisis bivariat menunjukan bahwa ada hubungan antara temperamen bayi dengan kondisi psikososial ibu postpartum ( $p$ value $=0,001)$. Bayi dengan temperamen tidak sulit berpeluang 12,56 kali untuk menciptakan kondisi psikososial ibu postpartum tidak berisiko $(\mathrm{OR}=12,56 ; 95 \%$ CI 4.35-36.4).

\section{Pembahasan}

Tingkat pendidikan ibu memengaruhi bagamaimana ibu akan menerima informasi mengenai perawatan bayinya. Ibu dengan tingkat pendidikan tinggi akan mudah untuk menerima informasi mengenai perawatan bayinya (Young, 2013).

Ibu primipara merupakan ibu yang baru pertama kali mempunyai anak. Pengalaman ibu dalam melakukan perawatan akan membantu ibu dalam merawat anak selanjutnya (Kinsey et al, 2014). Sedangkan status sosial ekonomi yang rendah akan berpengaruh pada bagaimana ibu memenuhi kebutuhan bayinya. Ibu dengan status ekonomi tinggi lebih mudah memenuhi kebutuhan bayinya ( Cornish, 2006).

Kondisi psikososial ibu pada masa postpartum berhubungan dengan bagaimana ibu akan merawat bayinya. Kondisi psikososial pada ibu postpartum terdiri dari riwayat kesehatan mental lalu, trauma fisik, pelecehan seksual ataupun gangguan emosional (Austin et al, 2011; \& Christl et al, 2013). Keadaan psikososial yang terganggu akan mengganggu kesejahteraan fisik maupun emosional ibu dan bayi (Drawett et al., 2004). Selain itu ibu dengan psikososial yang berisiko membuat ibu tidak percaya diri dalam perawatan terhadap bayinya (Moynihan, 2014).

Kondisi psikososial pada ibu yang terganggu berhubungan dengan perilaku ibu terhadap bayinya. Ibu dengan kondisi stress, cemas maupun depresi menyebabkan ibu kurang beraktivitas, kurang responsif dan jarang bermain atau berkomunikasi dengan bayinya (Austin, 2005).

Ibu dengan gangguan emosional dapat menunjukan keadaan emosi yang labil sehingga memunculkan perasaan tidak nyaman dengan bayinya, depresi, dan menurunkan sensitivitas serta ketertertarik dengan bayinya. Kondisi psikososial yang berisiko karena riwayat trauma fisik masa lalu cenderung membuat ibu untuk melakukan kembali pada bayinya, tidak melakukan perawatan serta menelantarkan bayinya. Kondisi psikososial ibu yang tidak sehat akan menyebabkan ibu berfokus pada diri sendiri. Selain itu ibu dengan psikososial yang berisiko membuat ibu tidak percaya 
diri dalam perawatan terhadap bayinya (Moynihan, 2014).

Remaja mempunyai status emosional yang masih labil (Khan, 2011). Remaja yang belum mampu memberikan perawatan, tidak siap menerima kehadiran bayinya merasa tidak berharga dan membenci bayinya (Perez, 2007). Status emosional yang labil, harga diri yang menurun pada remaja dapat menggangu pengasuhan. Hal ini yang menyebabkan usia merupakan salah satu faktor risiko dalam pengasuhan anak.

Penelitian Andreozzi et al (2002) menunjukkan tidak ada perbedaan yang signifikan hubungan antara ibu dan bayi pada ibu remaja dan dewasa, tetapi ada perbedaan karakteristik peran ibu yang signifikan antara ibu remaja dengan ibu dewasa. Perbedaan yang signifikan tersebut adalah ibu remaja mempunyai harga diri yang rendah, stress menjadi orang tua dan mempunyai kualitas yang rendah dalam memenuhi kebutuhan di rumah. Hal ini menunjukan bahwa usia merupakan salah satu faktor pendukung adanya kondisi psikososial ibu

Status ekonomi berhubungan dengan kondisi psikososial ibu. Ibu yang mempunyai status ekonomi tinggi mempunyai kesempatan memperoleh dukungan dalam mempersiapkan kebutuhan bayinya sejak awal kehamilan yang akan meningkatkan hubungan emosi ibu serta membantu ibu dalam melakukan peran pengasuhan serta berperan menjadi ibu (Cornish, 2006).

Pendidikan merupakan faktor demografi dalam psikososial ibu. Bussel (2010) bahwa semakin tinggi pendidikan ibu semakin baik hubungan dengan bayinya. Ibu dengan pendidikan tinggi lebih mudah menerima informasi mengenai pengasuhan bayi.

Temperamen bayi merupakan salah satu perilaku bayi dalam menyampaikan kebutuhan, perasaan maupun ketidaknyamanan. Perilaku instingtif bayi melalui gerakan, tangisan akan mempengaruhi ibu dalam memberikan perawatan (Mayseless \& Scher, 2000). Ibu yang memahami bahasa isyarat bayi akan lebih mudah dalam memenuhi kebutuhan bayinya. Bayi yang tenang, tidak rewel dan mudah ditenangkan saat menangis akan membuat ibu dengan mudah memberikan perawatan Edhborg, Matthiesen, Lundh, \& Widstro (2005). Bayi yang mudah ditenangkan membuat ibu tenang dalam melakukan perawatan sehingga meningkatkan ikatan antara ibu dan bayi.

Temperamen bayi yang difficult atau sulit akan menyebabkan ibu sulit untuk berinteraksi. Kesulitan dalam memahami temperamen bayi akan mengurangi proses pengasuhan bayi. Kesulitan dalam melakukan pengasuhan akan menyebabkan ibu menjadi stress sehingga ibu akan mempengaruhi kondisi emosional ibu (Schermerhorn \& Bates, 2012). Sedangkan Plaza (2010) menunjukkan bahwa ibu dengan kondisi hubungan dan emosional yang baik akan mempresepsikan temperamen bayinya baik. Sedangkan Glover, 2011 menunjukan bahwa ibu dengan kondisi psikososial yang stabil akan membantu bayi dalam berperilaku baik.

\section{Simpulan}

kondisi psikososial ibu postpartum merupakan kondisi emosi, mental dan perilaku ibu. Kondisi ini dipengaruhi oleh temperamen bayi. Bayi yang mudah akan membantu ibu dalam pengasuhan yang menyenangkan sehingga mengurangi stress dan ketegangan emosi ibu. Selain itu 
kondisi psikososial ibu juga berhubungan dengan usia, pendidikan, paritas, dan sosial ekonomi.

Untuk mengantisipasi adanya gangguan psikososial ibu pada postpartum perlu adanya pengkajian risiko psikososial pada ibu postpartum. Penelitian ini perlu dikembangkan dengan melakukan penelitian pada ibu remaja untuk mengetahui hubungan antara kondisi psikososial ibu remaja pada masa postpartum.

\section{Referensi}

Agampodi, S., Agampodi, T., Wickramasinghe, N., Fernando, S., Chathurani, U., Adhikari, W.,..., Newlands, D. (2012). Productivity cost due to maternal ill health in Sri Lanka. PLoS One 7: e42333. doi:10.1371/journal.pone. 0042333

Alexander, P. C., Teti, L., \& Anderson, C. L. (2000) Childhood sexual abuse history and role reversal in parenting. Child Abuse Neglect, 24 (6), 829-838. doi:10.1016/S0145-2134(00)00142-3

Andreozzi, L., Flanagan, P., Seifer, R., Brunner, S., \& Lester, B. (2002). Attachment classifications among 18month-old children of adolescent mothers. Archives of Pediatrics \& Adolescent Medicine, 156 (1), 20-26. doi:10.1001/archpedi.156.1.20

Austin, M. P., Colton, J., Priest, S., Reilly, N., \& Hadzi-Pavlovic, D. (2011). The antenatal risk questionnaire (ANRQ): Acceptability and use for psychosocial risk assessment in the, 26 (1), maternity setting Women Birth. Journal Of The Australian College Of Midwives 17-25. doi : 10.1016/j.wombi.2011.06.002

Banyard, V. L., Williams, L. M., \& Siegel, J. A. (2003) The impact of complex trauma and depression on parenting: an exploration of mediating risk and protective factors. Child Maltreatment, 8(4), 334-349. doi: 10.1177/ 1077559503257106

Bussel, J. C. H. V.,Spitz, B., \& Demyttenaere, K. (2010). Three selfreport questionnaires of the early mother-to-infant bond: Reliability and validity of the Dutch version of the MPAS, PBQ and MIBS. Arch Womens Ment Health, 13, 373-384. doi 10.1007/s00737-009-0140-z

Christl, B., Reilly.N., Smith, M., Sims. D., Chavasse .F., \& Austin, M. P. (2013). The mental health of mothers of unsettled infants: Is there value in routine psychosocial assessment in this context?. Arch Womens Ment Health, 16, 391-399 . doi 10.1007/s00737-0130360-0

Colman, R. A., \& Widom, C. S. (2004). Childhood abuse and neglect and adult intimate relationships: a prospective study. Child Abuse Neglect, 28(11), 1133-1151.doi:10.1016/j.chiabu. 2004.02.005

Cornish,M.A., McMahon,C.A., Ungerer, J.A., Barnett,B., Kowalenko,N.,\& Tennant,C. (2006). Maternal depression and the experience of parenting in the second postnatal year. Journal of Reproductive and Infant Psychology, 24(2), 121-132. doi: $10.1080 / 02646830600644021$

Drewett, R., Blair, P., Emmett, P., Emond, A., \& The ALSPAC Study Team. (2004). Failure to thrive in the term and preterm infants of mothers depressed in the postnatal period : A populationbased birth cohort study. $J$ Child Psychol Psychiatry, 45 (2), 359 - 366.

Edhborg, M., Matthiesen, A.S., Lundh, W., \& Widstro, A. M. (2005). Some early indicators for depressive symptoms and bonding 2 months postpartum - a study of new mothers and fathers. Arch 
Womens Ment Health, 8: 221-231 doi: $10.1007 / \mathrm{s} 00737-005-0097-5$

Glover, V. 2011. The Effects of Prenatal Stress on Child Behavioural and Cognitive Outcomes Start at the Beginning. Encyclopedia on Early Childhood development

Khan, S. A. (2011). Baby steps: A bonding program for adolescent mothers and their infants. Dissertation. Retrived from http://search.proquest.com/ $\% 20$ docview/

1103346632/4C6E2FE949C1458FPQ/ 1 ?accountid $=17242$

Kinsey, C. B., Baptiste- Roberts, K., Zhu, J., \& Kjerulff, K. H. (2014). Effect of miscarriage history on maternal-infant bonding during the first year postpartum in the first baby study: A longitudinal cohort study. BMJ Women's Health. 14:83. Retrived from http://www.biomedcentral.com /1472$6874 / 14 / 83$

Mayseless, O. \& Scher, A. (2000). Mother's attachment concerns regarding spouse and infant's temperament as modulators of maternal separation anxiety. Journal of Child Psychology and Psychiatry, 4 (7), 917-925. Retrived from

http://www.ncbi.nlm.nih.gov/pubmed/1 107943

Moynihan, M. (2014). Maternal attachment in close relationships, mother-infant postpartum bonding, and mentalization. Thesis. Retrived from proquest.com/

docview/1535344243/883D70E17B548A

APQ/ 1 ? accountid $=17242$

Muzik, M., Bocknek, E. l., Broderick, A., Richardson,P., Rosenblum,L.K., Thelen, T., \& Seng, J. S. (2013) . Mother-infant bonding impairment across the first 6 months postpartum: The primacy of psychopathology in women. with childhood abuse and neglect histories. Arch. Womens Ment. Health , 16, 29 - 38. doi: 10. 1007/s00737-012-0312-0

Perez, C. M. (2007). The relationship of mothers' emotional states To motherchild bonding among Latina mothers. Thesis of Degree, Master of Social Work, The Department of Social Work California State University, Long Beach. Available from Proquest UMI Dissertation Publishing database. (UMI Number : 1448969)

Plaza, M. B. (2010). Factors predicting maternal perceptions of child's temperamentin a group of African american and dominican women at risk for psychological distress: Constructing a model from recalled early maternal bonding, adult maternal attachment and maternal demoralization. Doctor of Philosophy Dissertation, The Graduate School of Arts and Sciences, Columbia University. Available from Proquest UMI Dissertation Publishing database. (UMI Number : 3447975)

Priest, S. R., Austin, M. P., Barnett, B. B., \& Buist, A. (2008). A psychosocial risk assessment model (PRAM) for use with pregnant and postpartum woman in primary care settings. Arch Womens Ment Health, 11, 307-317. doi : 10.1007/200737-008-0028-3

Rodgers, C. S., Lang, A. J., Laffaye, C., Satz, L. E., Dresselhaus, T. R., \& Stein, M. B. (2004). The impact of individual forms of childhood maltreatment on health behavior. Child Abuse Neglect, 28(5), 575-586. doi:10.1016/j. chiabu.2004.01.002

Schermerhorn, A.C., \& Bates, J.E. 2012. Temperament, Parenting and Implications for Development. Encyclopedia on Early Childhood development. 